\title{
An investigation of the processability of natural fibre reinforced polymercomposites on shallow and flat thin-walled parts by injection moulding process.
}

\begin{abstract}
Currently, many industries are trending towards producing products exhibit such properties as small thickness, lightweight, small dimensions, and environmental friendliness. In this project, flat or shallow thin-walled parts were designed to compare the advantages and disadvantages of lignocellulosic polymer composites ( $\mathrm{PP}+50 \mathrm{wt} \%$ wood) in terms of processability. This study focused on the filling, in-cavity residual stresses and warpage parameters associated with both types of thin-walled moulded parts. Thin-walled parts 0.7 $\mathrm{mm}$ in thickness were suitably moulded using lignocellulosic composite materials to determine the effects of filling. The analysis showed, the shallow thin-walled part is preferable in moulding lignocellulosic polymer composite material due to the low residual stress and warpage measured. The results also indicate that the shallow thin-walled part is structurally rigid, such that it can be used in applications involving small shell parts, and can be processed more economically using less material than the flat thin-walled part.
\end{abstract}

Keyword: Natural fibre reinforced polymers; shallow and flat thin-walled parts; injection moulding process 